\title{
Autonomic Neuropathy in the Streptozotocin Diabetic Rat
}

\author{
GEORGE MONCKTON AND ENID PEHOWICH
}

SUMMARY: An ultrastructural study of the sympathetic ganglia, dorsal sympathetic chain, and Auerbach's plexus is described in the streptozotocin diabetic rat. The observations cover the first six weeks following induction of diabetes. Degenerative changes began to appear in the axonal plasma membranes and axoplasm of unmyelinated fibers at 24 hours and were widespread by two weeks. Axonal sprouting and regenerating axons began to appear and increase in number through the oth week. Chromatolysis in ganglion cells

RESUMÉ: Nous décrivons chez le rat rendu diabétique par la streptozotocine une étude ultrastructurelle des ganglia sympathiques, de la chaîne sympathique dorsale et du plexus d'Auerbach. Les observations couvrent les premières six semaines suivant l'induction du diabète. Les changements dégénératifs commencent dès les premiers 24 heures au niveau des membranes plasmatiques axonales et de l'axoplasme des fibres non myélinisées et sont généralisées à la deuxième semaine. Les embranchements axonaux et les axones en regénérescence apparaissent et augmentent en nombre jusqu'à la $6 e$ in sympathetic ganglia became apparent by two weeks as did degenerative changes in axons of Auerbach's plexus. This somewhat later appearance of changes in ganglion cells and Auerbach's plexus suggested the primary changes occurred in the postganglionic fibers. The cycle of change from degeneration to regeneration in the areas examined suggests either $a$ possible toxic effect of streptozolocin or a combination of metabolic disturbances as a cause of this neuropathy.

semaine. La chromatolyse des cellules ganglionnaires des ganglions sympathiques devient apparente vers la deuxième semaine. Il en est ainsi des changements dégénératifs dans les axones du plexus d'Auerbach. Cette apparition plus tardive des changements dans les cellules ganglionnaires et le plexus d'Auerbach suggère que les manifestations primaires se produisent dans les fibres postganglionnaires. Le cycle d'évolution de dégénérescence à régénérescence dans les aires examinées suggère soit un effet toxique de la streptozotocine, soit une combinaison de troubles métaboliques comme cause de cette neuropathie.
From the Department of Medicine (Neurology), University of Alberta, Edmonton, Alberta, Canada.

Supported by a grant from the Canadian Diabetic Association.

Reprint requests to Dr. George Monckton, 9-101 Clinical Sciences Bldg., 11282 - 84th Avenue. Edmonton, Alberta. T6G 2G3, Canada.
A number of studies of experimental neuropathy have been made in the streptozotocin diabetic rat. The majority of these investigations concern themselves with changes in conduction rates and the histology of the peroneal and other peripheral nerves. While mention of unmyelinated fibers is made in discussions of the peroneal nerves, no study appears to have been carried out on the autonomic nervous system. This paper is concerned with the changes observed serially in the dorsal sympathetic chain, sympathetic ganglia, and Auerbach's plexus at varying intervals following induction of diabetes by streptozotocin.

\section{METHODS}

Female Wistar albino rats, six weeks of age, weighing between 125 and 150 grams were used in this study. Six normal rats were used as controls and 21 were rendered diabetic by the intravenous injection (foot vein) of streptozotocin (Upjohn) in doses of $80 \mathrm{mgm} /$ $\mathrm{kgm}$. Blood glucose analysis was made immediately prior to sacrifice. At one day, three days, seven days, fourteen days, and six weeks, the animals were injected intraperitoneally with sodium pentobarbitol in lethal doses. Segments of the jejunum were removed for fixation. Twenty $\mathrm{ml}$ of Tyrode buffer at $\mathrm{pH} 7.4$ was perfused through an intra-aortic catheter followed by 200 $\mathrm{ml}$ of $2 \%$ glutaraldehyde in $0.1 \mathrm{~m}$ of cacodylate buffer $\mathrm{pH}$ 7.4. This perfusion was followed by $20 \mathrm{ml}$ of Tyrode buffer as above, then $40 \mathrm{ml}$ of $1 \%$ osmium tetroxide in phosphate buffer at $\mathrm{pH}$ 7.4. Dissection and removal of the sympathetic chains and ganglia was carried out. Following postfixation in osmium, the material was dehydrated and embedded in Epon 812 (Luft, 1961).

Sections of sympathetic chains 
below the fifth dorsal ganglion were cut starting $4 \mathrm{~mm}$ below the border of the fifth ganglion. Sections were cut so that 5 one micron serial sections and 10 thin serial sections were cut at five micrometer intervals from each millimeter segment of chain. Thin sections were stained with uranyl acetate and lead citrate and examined and photographed in a Siemens L-102 electron microscope. From this information, the sizes of Schwann cell units, crosssectional diameter of axons, and ultrastructural changes were determined.

Sections of jejunum were examined at light and EM levels.

Measurement of nerve fiber areas was carried out by using squared semi-transparent paper. Diameters were calculated from the measured fiber areas, assuming a circular profile. Schwann cell unit size was determined by examination of serial sections of the sympathetic chain.

\section{RESULTS}

Morphometric analysis of the dorsal sympathetic chain from streptozotocin induced diabetic rats is summarized in Figures 1 and 2. It can be seen that there was a profound drop in the mean of areas and diameters of the axons by the third day. The distribution of fiber size showed a general shift of the mean of axonal diameters to the left in the treated rats. There was a

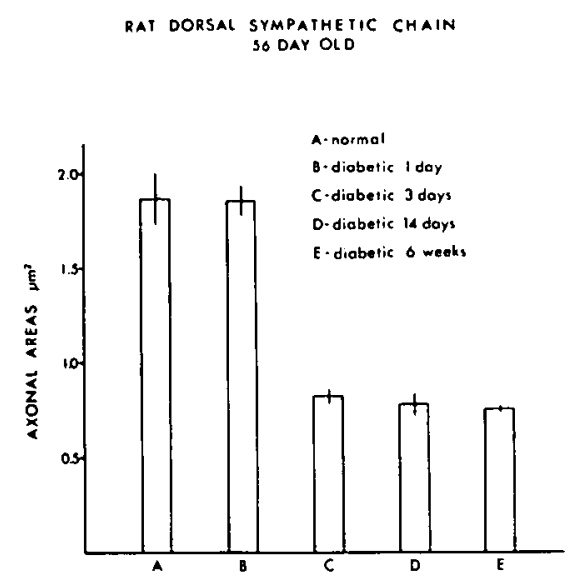

Figure $l$ - Rat dorsal sympathetic chain. There is a drop in the mean of axonal areas by the third day which does not recover by the sixth week. Bars represent standard deviation. wider spread of fiber representation at three days and two weeks. There was some reduction of this spread at six weeks with a more homogeneous small fiber residual axonal representation. Schwann cell unit sizes tended to become smaller by the third day with some recovery by six weeks.

\section{ULTRASTRUCTURAL OBSERVATIONS}

\section{A. 24 hours}

Twenty-four hours after injection, the rats were not eating and were sick. They were beginning to demonstrate polyuria and had a rising blood sugar.

\author{
AXON DIAMETER DISTRIBUTION \\ IN NORMAL AND DIABETIC RATS
}
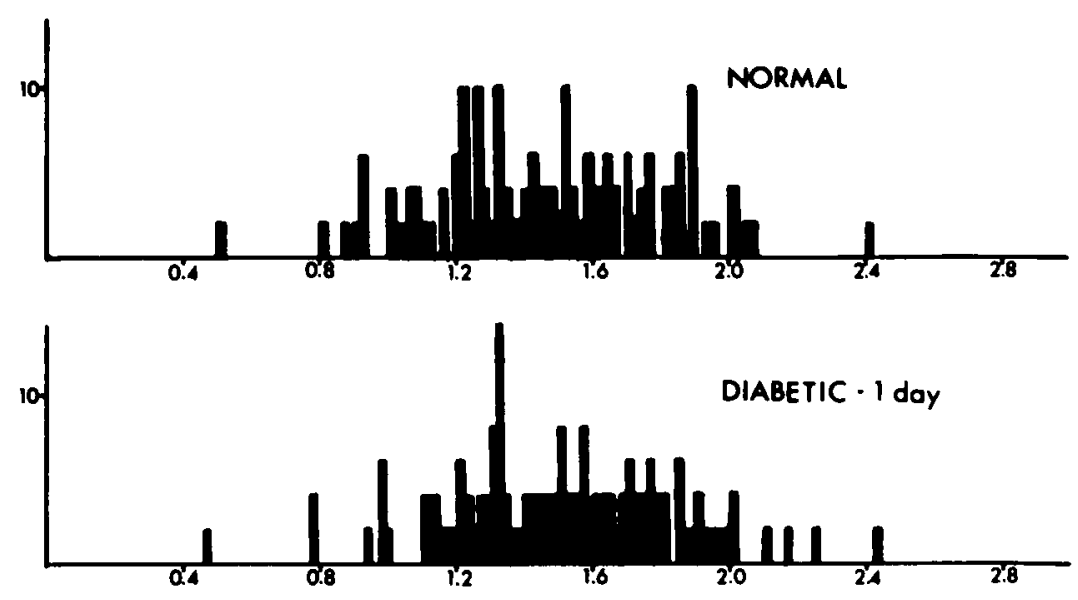

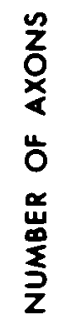
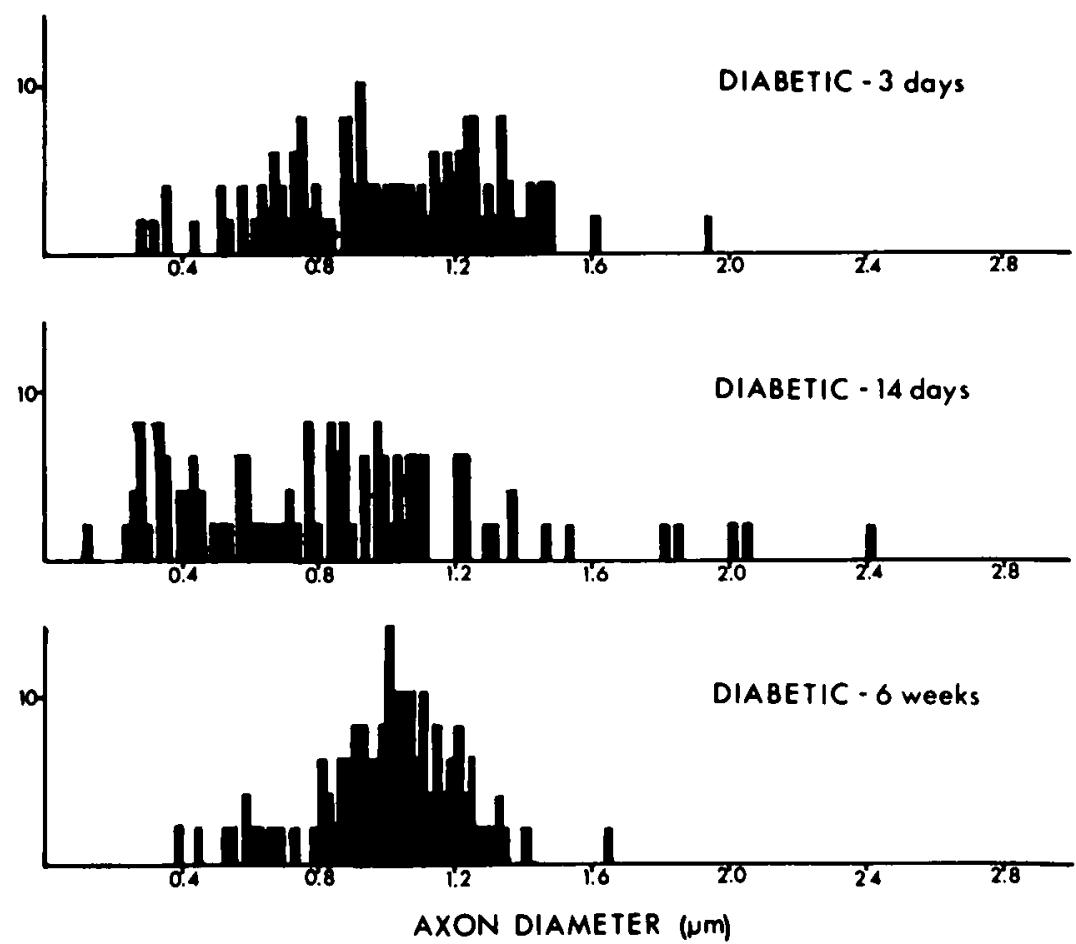

Figure 2 - Rat dorsal sympathetic chain. The distribution of fiber size shows a general shift of the mean of axonal diameters to the left in the treated rats. There is a wider spread of fiber representation at three days and two weeks. There is some reduction of this spread at six weeks with a more homogeneous small fiber residual axonal representation. 
Ultrastructural changes were slight and, as indicated in Figures 1 and 2, there was little difference in morphometry of the dorsal sympathetic chain. Ultrastructural changes, however, could be seen. (Compare these with Fig. 3). Thus, there were irregularities in the plasma membrane which in some axons was missing or broken. Some of the axons showed a paucity of intraaxonal organelles, giving a patchy, watery-look to the axoplasm (Fig. $4 \mathrm{a}$ ); some axons had lost their internal architecture totally (Fig. 4b). These axonal changes were relatively infrequent and there were areas in the sections where no obvious abnormality could be seen. In the myelinated nerve fibers, there were no obvious changes.

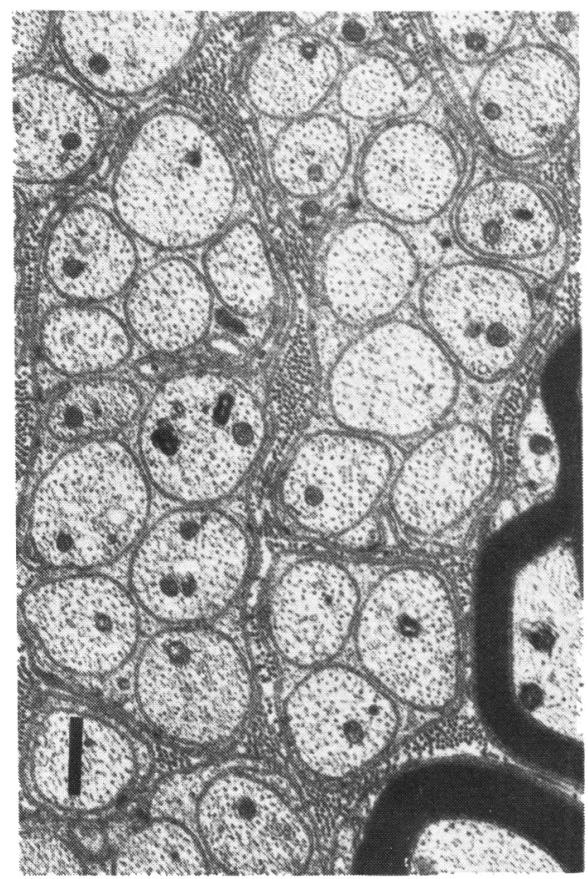

Figure 3 - Normal Schwann cell units. Bar $=0.7 \mu \mathrm{m}$

\section{B. Three days}

At three days, there was an increase in the number of obviously diseased axons in which the axoplasm was washed-out and relatively featureless (Fig. 5a). There did not seem to be any specific organelle pathology within the axons, but rather a diffuse loss of these together with some clumping of the axoplasm. Mitochondria showed varying degrees of swelling. Occasionally,
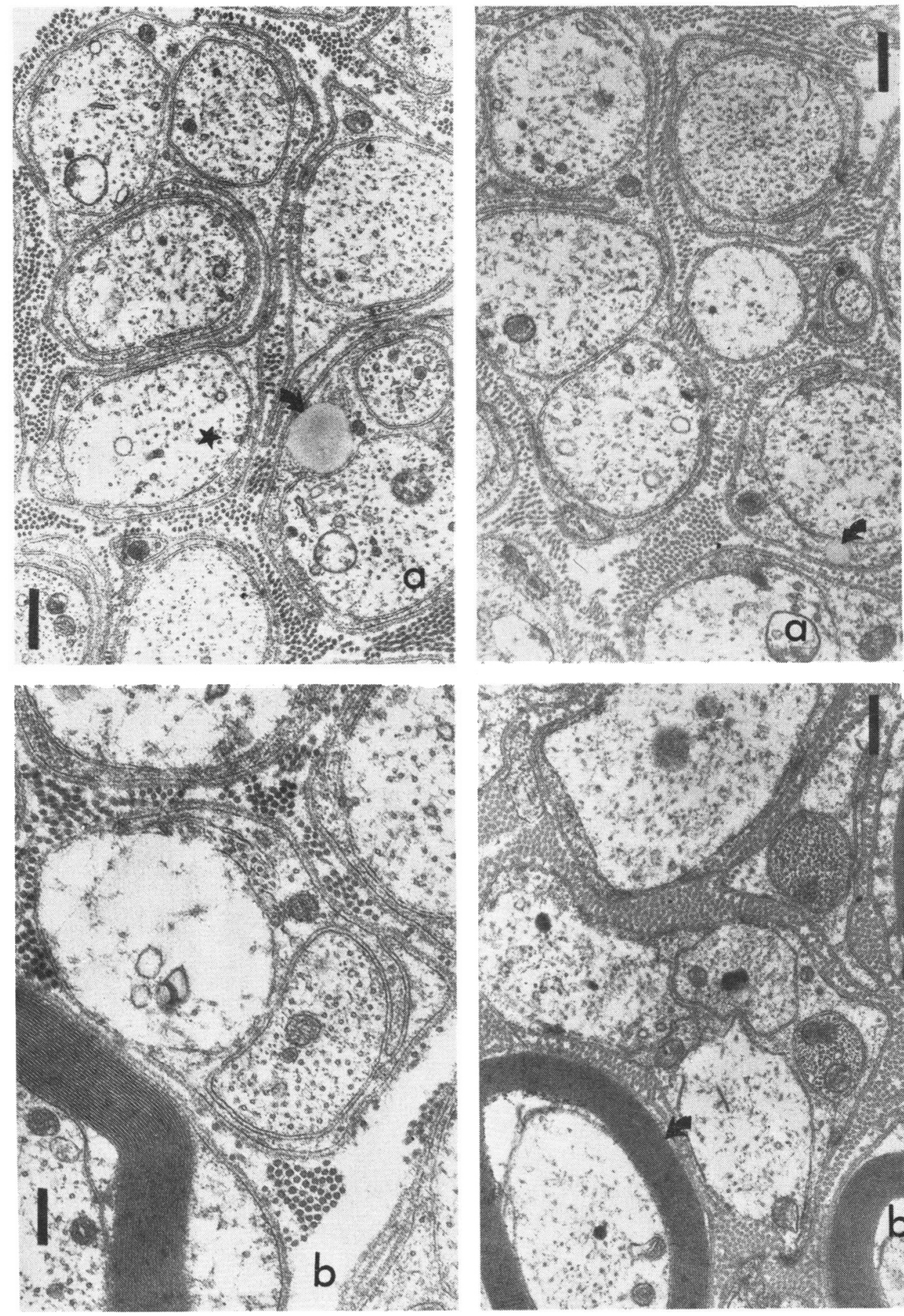

Figure 4 - Dorsal sympathetic chain at 24 hours following injection of streptozotocin.

a) Axon marked with a star shows moth-eaten plasma membrane and early "washing-out" of axoplasm. Note lipid globule (arrow) Bar $=0.4$ $\mu \mathrm{m}$

b) More advanced degenerative changes in axon with very little recognizable axoplasm remaining. A group of four vesicles of irregular type. Note also gross plasma membrane changes in affected axon. Bar $=0.25$ $\mu \mathrm{m}$

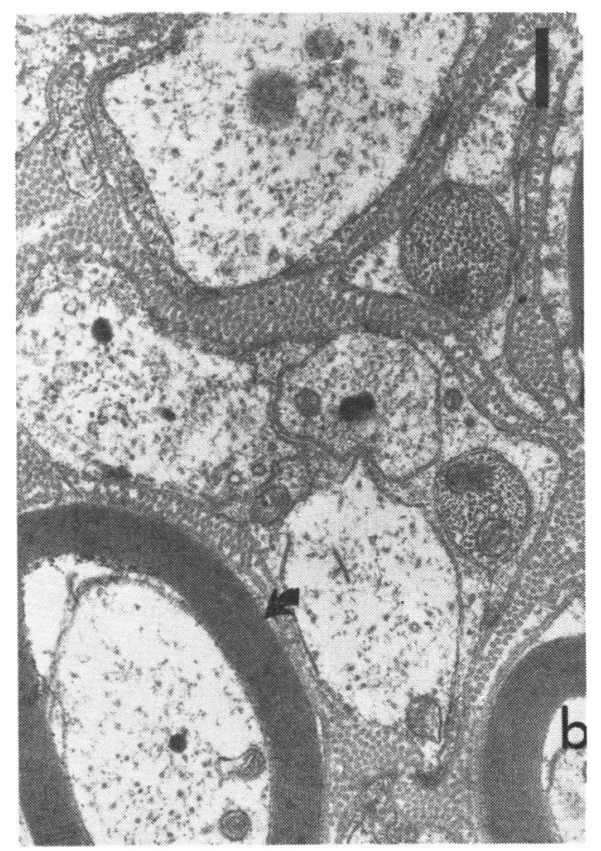

Figure 5 - Dorsal sympathetic chain at 3 days following injection of streptozotocin.

a) A group of axons showing varying degrees of degenerative change. Lipid inclusion indicated by arrow. Bar $=0.4 \mu \mathrm{m}$

b) Several severely affected axons with various types of vesicles and axoplasmic change. Three smaller and probably regenerating axons are seen. The myelinated fiber (arrow) shows abnormal axoplasm. Bar $=0.4$ $\mu \mathrm{m}$ 
in association with the abnormal axons, there could be seen very small axonal sprouts as a first indication of attempted regeneration (Fig. 5b). For the first time there appeared to be a reduction in the size of the Schwann cell units so that it was commonplace to find one or two axons within a Schwann cell's territory, and the average Schwann cell unit size was three to four axons per Schwann cell. This was in contrast to the normal eight to fourteen axons. Schwann cell cytoplasm appeared denser and more closely packed. No specific pathological change was seen otherwise. Occasional myelinated fibers were beginning to show changes in their axoplasm similar to those seen in the early stages of involvement of nonmyelinated fibers (Fig. 5b).

\section{Two Weeks}

After two weeks degeneration and regeneration appeared in which the regenerative effort was becoming more definite. There were many axons which contained washed-out axoplasm with patchy loss of tubules, neurofibrils, and swollen mitochondria. Some small axons were evident (Fig. 6 a, b, \& c). Some of these were sprouts and some of them were regenerating axons. Occasional myelinated fibers were seen showing relatively severe changes with distortion of the myelin sheath and evidence of myelin figures in the cytoplasm (Fig. 6d). The Schwann cells continued to have dense cytoplasm. There was an apparent increase in the amount of collagen present.

\section{Six Weeks}

At six weeks regeneration exceeded degeneration although bloated, waterylooking axons were seen which were undergoing degenerative changes. Most of the axons were small and packed with organelles. They had the appearance of rapidly regenerating axons (Fig. 7 a \& b). The Schwann cell unit size appeared to be increasing with some Schwann cell units having four or five axons of varying sizes. The Schwann cells had a more normal appearance with less dense cytoplasm.
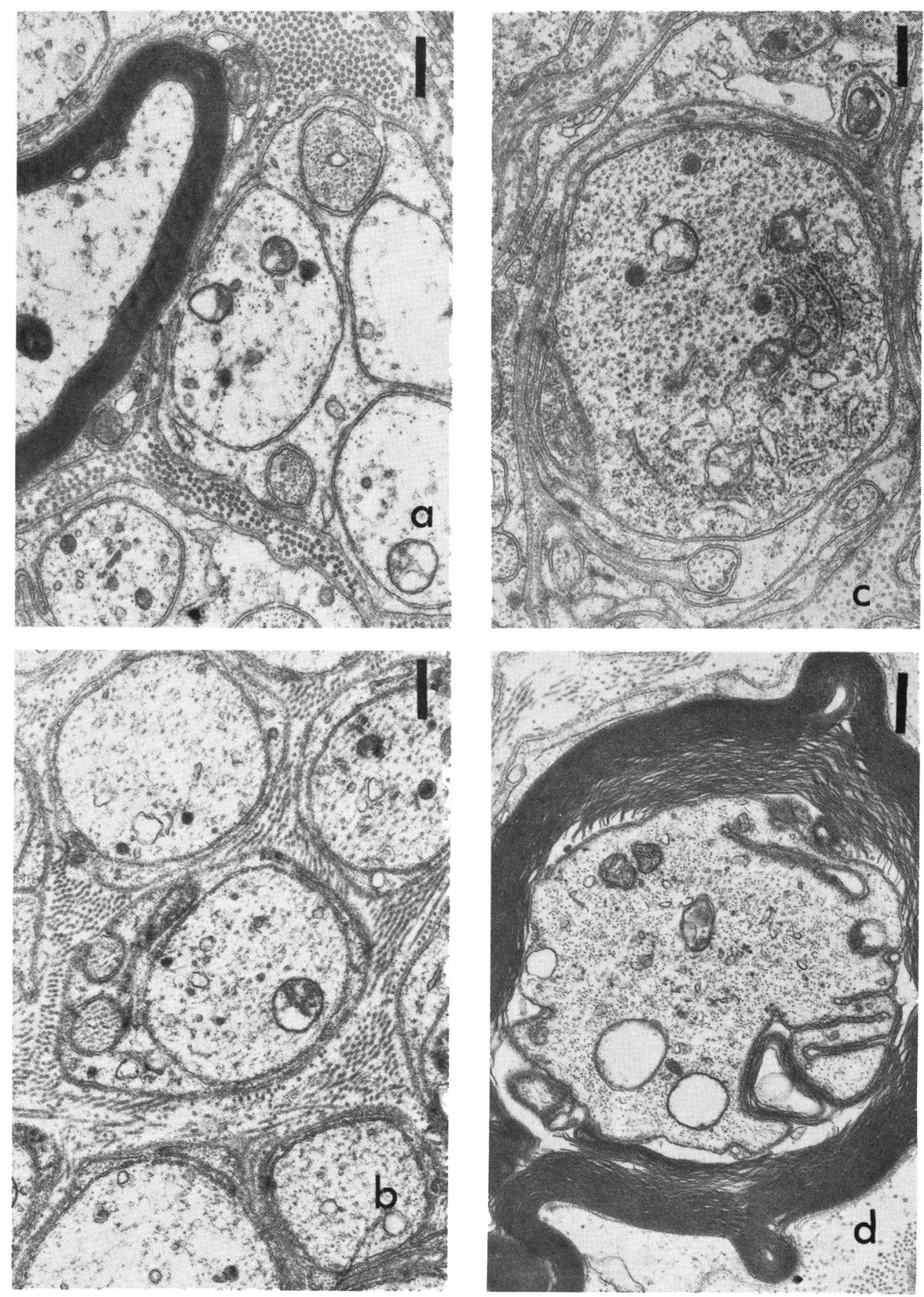

Figure 6 - Dorsal sympathetic chain 2 weeks following injection of streptozotocin.

a) Severely degenerated axon in a Schwann cell unit associated with two probably regenerating axons. Bar $=0.4 \mu \mathrm{m}$

b) A group of axons in varying stages of degenerative change and two regenerating axons. Note various

The apparent increase in collagen persisted. Changes in myelinated nerve fibers were still noted occasionally, as described at two weeks. stages of vesicles in axoplasm. Bar = $0.4 \mu \mathrm{m}$

c) Schwann cell, with large axon containing endoplasmic reticulum, associated with a number of smaller regenerating axons with bizarre and long mesaxons. Bar $=0.4 \mu \mathrm{m}$

d) Grossly abnormal myelinated axon. Bar $=0.4 \mu \mathrm{m}$

\section{GANGLION CELLS OF THE} SYMPATHETIC CHAIN

\section{Light Microscopy}

At 24 hours little change could be 

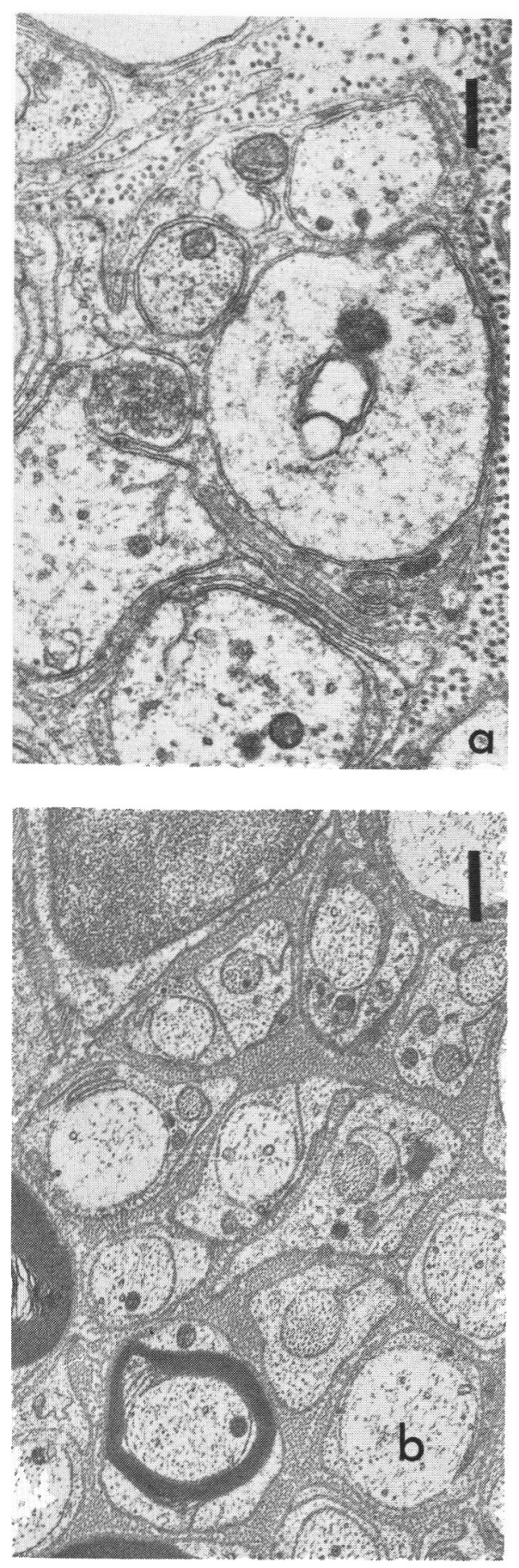

Figure 7 - Dorsal sympathetic chain 6 weeks following injection of streptozotocin.

a) Degenerative changes are still in evidence. Collection of vesicles in center of micrograph probably related to transmitter (cholinergic?) substance. Bar $=0.4 \mu \mathrm{m}$

b) Regenerating small axons with long and tortuous mesaxons. Bar $=0.8$ $\mu \mathrm{m}$
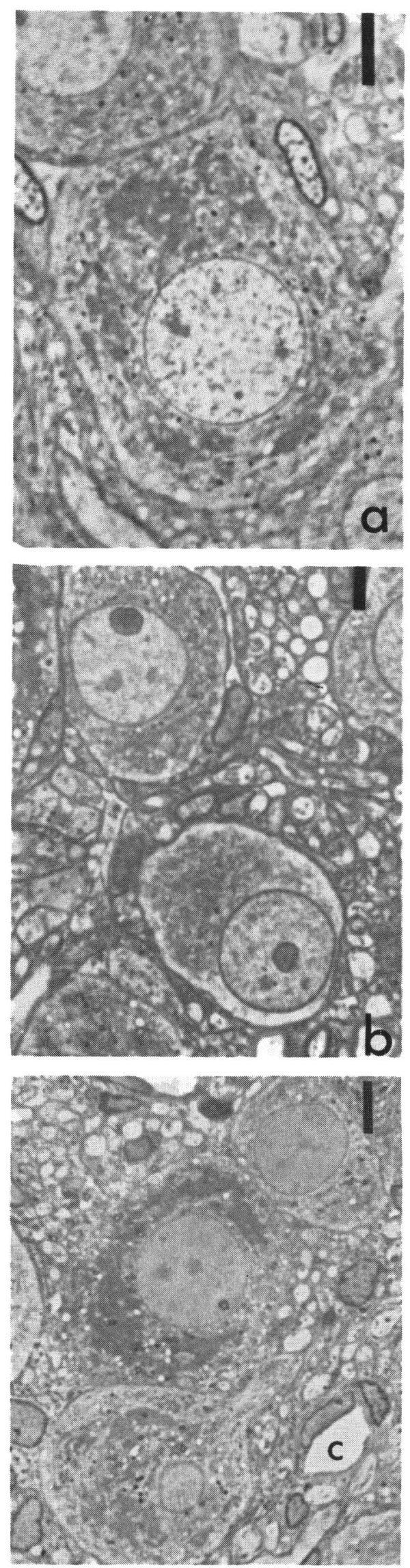
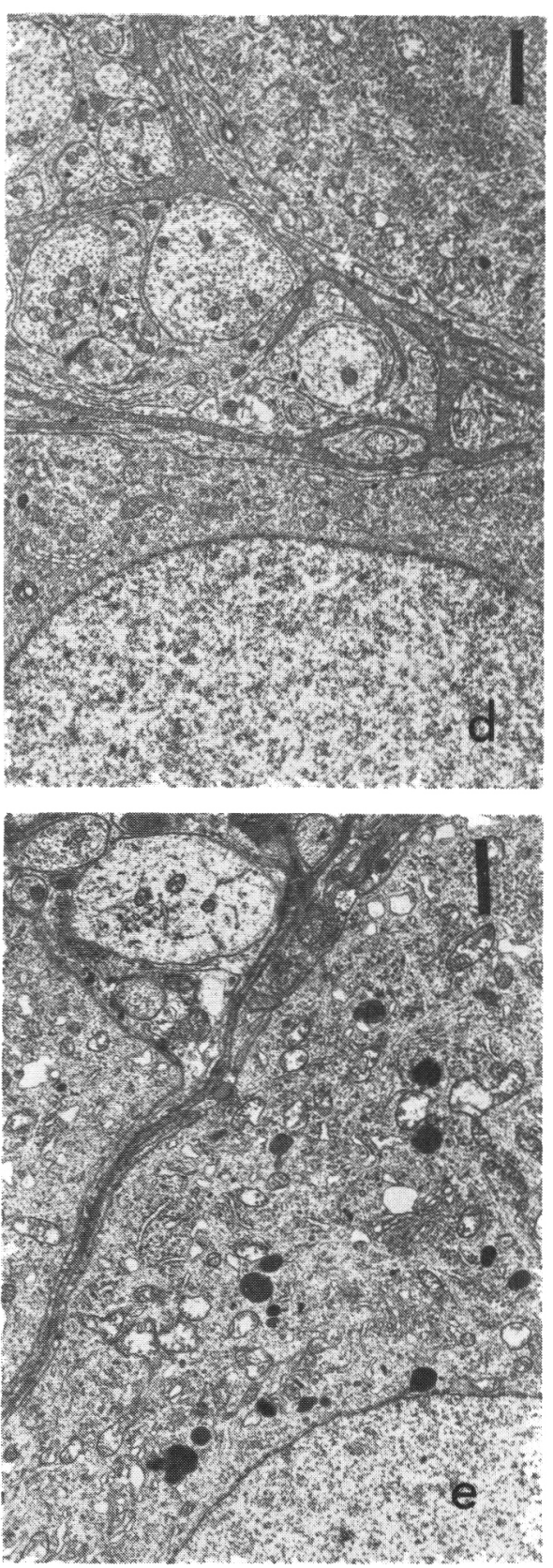

Figure $8-$ Ganglion cells of dorsal sympathetic chain.

a) Light micrograph. Normal ganglion cell. Bar $=5.5 \mu \mathrm{m}$

b) Light micrograph showing marginated nuclei of ganglion cells at 2 weeks. Bar $=5.5 \mu \mathrm{m}$

c) Ganglion cells at 6 weeks. Note variation in cytoplasmic Nissl staining. Light micrograph. Bar $=5.5 \mu \mathrm{m}$

d) Normal ganglion cell. Electron micrograph. Bar $=0.5 \mu \mathrm{m}$

e) Ganglion cell at 3 days. Note vesicular activity and lysosomes. Intraganglionic axons show early degenerative changes as in dorsal sympathetic chain. Bar $=1.25 \mu \mathrm{m}$ 
seen in the ganglion cells (Fig. 8a). From three to fourteen days a number of cells appeared to have abnormally dispersed Nissl substance and to be pale staining. This was associated with an eccentric positioning of the nucleus which occasionally was located at the margin of the cell (Fig. 8b). Some nuclei appeared to have no stained chromatin, even at high power with phase contrast. At 14 days some ganglion cells appeared shrunken, poorly stained, and degenerating.

By six weeks there was a more obvious mixed population of ganglion cells. Some were noted to have deeply stained cytoplasmic masses of Nissl substance and nuclei with visible chromatin and heavily-stained nucleoli. Other ganglion cells were small and more palely staining with apparently less Nissl substance (Fig. 8c).

At the EM level examination showed increased vesicular activity in the cytoplasm of affected ganglion cells. In these cells increased numbers of lipid laden lysosomes of varying sizes were seen. Vesicles of other types were also present in considerable numbers. This activity was difficult to appreciate before three days and was more evident by 14 days (Fig. $8 d$ \& e). The series of axonal changes described above were also to be seen in the intraganglionic axons.

\section{Auerbach's Plexus}

Ultrastructural examination of this intramural plexus showed little evidence of change at 24 hours (Fig. 9a). By one or two weeks occasional axons appeared swollen and had lost some axoplasmic definition with some increase in regular and irregular vesicle formation (Fig. 9b). Presynaptic vesicles appeared agranular in type and normal in appearance. By six weeks, degenerative changes with axonal ballooning was well-marked. There were also small regenerating axons (Fig. 9c).

In summary, the changes which were seen serially in the dorsal sympathetic chain following induction of diabetes by injection of streptozotocin, commence within 24 hours with some washing-out of neurofilaments and tubules in a patchy fashion with evidence of breakages in the plasma
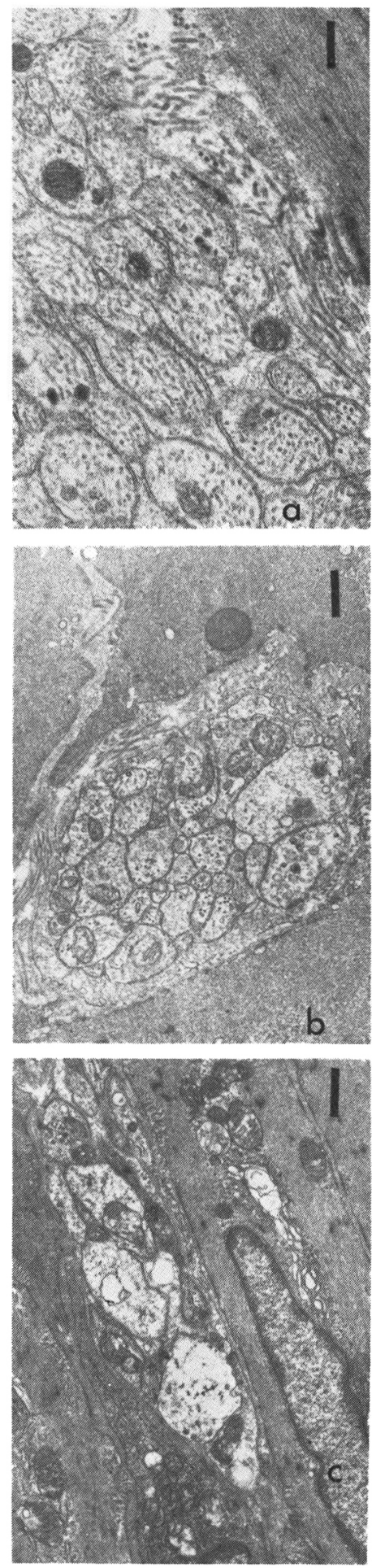

Figure 9 - Auerbach's plexus

a) Auerbach's plexus from normal jejunum. Section is obliquely cut. Bar $=0.3 \mu \mathrm{m}$

b) Seven days following induction of diabetes showing distended degenerative axon. Bar $=0.5 \mu \mathrm{m}$

c) Continued degenerative changes seen with some regenerating axons at 6 weeks. Bar $=0.8 \mu \mathrm{m}$ membrane. This was followed by widespread degeneration of axons which first become watery and possibly slightly swollen, and then are replaced by active axonal sprouting and axonal regeneration. By six weeks, degenerative fibers were still present, but many of the axons present were either regenerating or appear undamaged. At six weeks, the Schwann cell units remained small. The mean of axonal diameters were approximately half the normal size.

The ganglion cells also showed a cycle of events starting from one to three days with the development of chromatolysis, leading to regenerative changes at six weeks with some continuing, occasional ganglion degeneration.

\section{DISCUSSION}

Pathological and physiological studies of the autonomic nervous system in experimental diabetes have been largely confined to the peripheral nerves. Eliasson $(1964,1969)$, Seneviratne and Peiris (1969) showed that in the alloxan diabetic rat changes in conduction in the peripheral somatic nerves occurred within a few days of treatment and began to improve after 10 to 14 days, never fully recovering. More recently, this aspect of experimental diabetic neuropathy has been studied in detail by Jakobsen (1976) and Jakobsen and Lundbaek (1976), using streptozotocin induced diabetic rats. These papers were concerned with the problem of an apparent reduction in size of myelinated axons following induction of diabetes of varying duration. Their conclusion that the delayed nerve conduction was related to reduction of axonal diameters was criticized by Thomas and Sharma (1976) and Sharma et al (1977), who felt there were no changes in myelinated axon fiber sizes and that reduced nerve conduction velocity should be correlated with metabolic disturbances rather than structural changes. However, Jakobsen (1979), in a morphometric study, provided evidence of a $30-40 \%$ reduction in diameter of myelinated axons of the peroneal nerve in the rat.

Investigators have mentioned nonmyelinated fibers in the peroneal and radial nerve, but, beyond commenting 
on the lack of pathological change after extended periods of diabetes, did not otherwise examine the autonomic nervous system. Sharma and Thomas (1974) examined the vagus nerve in rats at 25,28 , and 49 weeks following induction of diabetes with streptozotocin, but demonstrated no abnormality.

The serial changes that we report were seen in the six weeks following induction of diabetes when other investigators do not appear to have examined their material. Sharma and Thomas (1974) examined peroneal nerves at three and six weeks and found no pathological change. Possible explanations for this might be that our animals were all juvenile, weighed no more than 150 grams, and we used streptozotocin in doses of 80 $\mathrm{mgm} / \mathrm{kgm}$ given intravenously. Sharma and Thomas used various doses from $50-100 \mathrm{mgm} / \mathrm{kgm}$ of streptozotocin given intraperitoneally into adult rats with body weights of 250 300 grams. As indicated in our report, regenerative changes are well in hand by six weeks and might reasonably be expected to continue. Finally, other workers have not examined the dorsal sympathetic chain or Auerbach's plexus in this experimental setting. The discrepancies between our findings and those of earlier workers may be accounted for by all these factors.

In our series of rats, the changes we have described are not specific. Many of these changes were described by Matthews and Raisman (1969), Dyck and Hopkins (1972), and extensively reviewed by Gabella (1976) as a result of postganglionic section of the cervical sympathetic chain in rats. Because of a marked similarity in the changes observed by us to those described above and the time lapses between axonal changes in the sympathetic chain and ganglion cells and Auerbach's plexus, we believe that the ictus of the pathogenic factor(s) is on the postganglionic fibers. One of the earliest changes in our series, which is at variance with the described pathology of postganglionic nerve section, is the demonstration of early plasma membrane breakdown with preservation of the basement membrane and may relate to more specific membrane involvement.
In considering the causes of the severe changes that occur so early following induction of diabetes, the question arises as to whether this neuropathy is related to the drug, the induced diabetes, or a combination of both. The resolution of this question is very important.

A review of the toxic effects of streptozotocin as described in the literature suggests that there may be several cellular sites where these effects occur. The most severe effect is seen to be upon nicotinamide adenine dinucleotide (N.A.D.) in beta cells of the pancreas and liver cells in the rat. In these cells, Gunnarsson et al (1978) showed a reduction of up to $90 \%$ of N.A.D. and this is associated with a drop in oxygen utilization. These effects are seen in association with reduced nerve conduction velocity. Importantly, the biochemical and nerve conduction changes may be prevented by treatment of the rats prior to induction of diabetes with nicotinamide.

A similar and important series of observations has been made demonstrating a reduction of myoinositol in whole sciatic nerves in streptozotocin diabetic rats (Greene et al, 1975) and a decrease in phosphatidyl inositol in whole nerve (Palmano et al, 1977), and these findings correlate with a reduced nerve conduction velocity. Both the reduced myoinositol and reduced motor nerve conduction velocity are preventable by giving the rats a $1 \%$ myoinositol diet prior to induction of diabetes.

In a freeze fracture study, Fukuma et al (1978) show alterations in myelin membranes of large sciatic nerve fibers in which protein particles are seen to be reduced 14 days after induction of diabetes by streptozotocin. This reduction was not present in rats treated with insulin or in diabetic rats fed a $1 \%$ myoinositol diet, but still remaining hyperglycemic. Because of the evident involvement of N.A.D. and myoinositol, one might reasonably expect structural changes in membranes as early evidence of cellular involvement and our observations would tend to support this.

Observations on the effects of streptozotocin on the beta cells of the pancreas and liver cells (Gunnarsson et al, 1978) and renal glomeruli (Cohen et al, 1977) leave no doubt that this substance has a widespread toxicity.

The demonstration that a $1 \%$ myoinositol diet prevents the alterations in internodal myelin membrane even though hyperglycemia persists (Fukuma et al, 1978) suggests a possible toxic role for streptozotocin. However, Eliasson (1964) and Miyoshi and Goto (1973) noted that those animals that did not become diabetic after alloxan administration did not develop any change in conduction velocity in peripheral nerves. Eliasson (1964) further showed that the pancreatectomized rats developed impaired nerve conduction of the same order as those treated with alloxan.

It seems clear from the conflicting evidence available that it is not possible to exonerate streptozotocin as a possible cause of the neuropathic changes described. In considering our results in this context, we think the time course of neuronal destruction and regeneration demonstrated by the morphometric analysis of fiber and Schwann cell unit size, as well as the cycle of ultrastructural changes, strongly suggests a toxic rather than a diabetic cause for the neuropathic changes we report.

\section{ACKNOWLEDGEMENT}

We acknowledge with thanks the help of Barbara Philips in the preparation and care of the animals in this project.

\section{REFERENCES}

COHEN, M.P. and KLEIN, C. (1977) Glomerulopathy in rats with streptozotocin diabetes. Journal of Experimental Medicine, 623631.

DYCK, P.J. and HOPKINS, A.P. (1972) Electron microscopic observations on degeneration and regeneration of unmyelinated fibres. Brain 95, 223-234.

ELIASSON, S.G. (1964) Nerve conduction changes in experimental diabetes. Journal of Clinical Investigation, 43, 2353-2358.

ELIASSON, S. G. (1969) Properties of isolated nerve fibres from alloxanized rats. Journal of Neurology, Neurosurgery and Psychiatry, 32, 525-529.

FUKUMA, M., CARPENTIER, J. L., ORCI, L., GREENE, D.A., and WINEGRAD, A.I. (1978) An alteration in internodal myelin membrane structure in large sciatic nerve fibers in rats with acute streptozotocin diabetes and impaired nerve conduction velocity. Diabetologia, 15, 65-72. 
GABELLA, G. (1976) The Structure of the Autonomic Nervous System. Chapman \& Hall London.

GREENE, D. A., DEJESUS, JR., P. V., WINEGRAD, A.l. (1975) Effects of insulin and dietary myoinositol on impaired peripheral motor nerve conduction velocity in acute streptozotocin diabetes. Journal of Clinical Investigation, 55, 1326-1336.

GUNNARSSON, R., BERNE, C., and HELLERSTROM, C. (1974) Cytotoxic effects of streptozotocin and $\mathrm{N}$. nitrosometh-ilurea on the pancreatic $B$ cells with special regard to the role of nicotinamide adenine dinucleotide. Biochemical Journal, 140 (3), 487-494.

JAKOBSEN, J. (1976) Axonal dwindling in early experimental diabetes. A study of cross-sectioned nerves. Diabetologia, 12, 539-546.

JAKOBSEN, J. (1979) Early and preventable changes of peripheral nerve structure and function in insulin-deficient diabetic rats. Journal of Neurology, Neurosurgery, and Psychiatry, 42, 509-518.

JAKOBSEN, J., and LUNDBAEK, K. (1976) Neuropathy in experimental diabetes. An animal model. British Medical Journal, 2, 278-279.

LUFT, J.H. (1961) Improvements in epoxy resin embedding methods. Journal of Cell Biology, 9, 409.

MATTHEWS, M.R. and RAISMAN, G. (1969) Ultrastructural changes in the superior cervical ganglion of the rat following constriction of efferent fibres. Journal of Physiology (London), 201, 11-13 P.

MIYOSHI, T., and GOTO, I. (1973) Serial in vivo determinations of nerve conduction velocity in rat tails. Physiological and pathological changes. Electroencephalography and Clinical Neurophysiology, 35, 125131.
PALMANO, K.P., WHITING, P.H., HAWTHORNE, J.N. (1977) Free and lipid myoinositol in tissues from rats with acute and less severe streptozotocin-induced diabetes. Biochemical Journal, 167, 229-235.

SENEVIRATNE, K.N., and PEIRIS, O.A. (1969) The effects of hypoxia on the excitability of the isolated peripheral nerves of alloxan-diabetic rats. Journal of Neurology, Neurosurgery, and Psychiatry, 32, 462-469.

SHARMA, A. K., and THOMAS, P.K. (1974) Peripheral nerve structure and function in experimental diabetes. Journal of the Neurological Sciences, 23, 1-15.

SHARMA, A.K., THOMAS, P.K., and DE MOLINA, A.F. (1977) Peripheral nerve fiber size in experimental diabetes. Diabetes, 26, 689-692.

THOMAS, P. K., and SHARMA, A. K. (1976) Neuropathy in experimental diabetes. British Medical Journal, 2, 478. 